\title{
Design and the Circular Economy in the UK blinds and shutter industry
}

\author{
Deborah Andrews, Zoe De Grussa, Andrew Chalk and Dave Bush
}

\section{Introduction}

Blinds and shutters are multi-functional products that have been used in residential and nonresidential buildings around the world for hundreds of years. The component, ready-made and bespoke shading product industry is well-established in the UK and annual turnover exceeds $£ 500$ million, which equates to between 4 and 5 million products. The design and manufacture of shading products means that they lend themselves to activities associated with the Circular Economy (CE) such as repair, refurbishment and recycling, which are carried out by many manufacturers and installers. Despite this good practice, many blinds and shutters are disposed of by building occupants even though they still work and the majority of them end up as waste in landfill or are incinerated and as a result of which a considerable quantity of resources is lost every year.

This chapter discusses the various reasons why this happens, beginning with a brief history of blinds and shutters and the development of the shading product manufacturing industry. It also describes their various functions, user behaviour and the impact of motorisation and automation on users and the potential of these technologies as drivers of a more extensive CE. Despite the various positive activities and behaviours, there are a number of challenges to 
circularity but these are not unsurmountable and the chapter concludes with a series of design proposals that will help to overcome these challenges.

\section{History and context}

Blinds and shutters have been used around the world for hundreds of years to cover unglazed and glazed window openings, although the precise origin and date of invention is unknown. Early examples were made from natural materials including wooden slatted 'venetian' blinds, which were introduced from Persia to Europe and America. Since the middle of the eighteenth century there have been numerous patented and unpatented innovations, and currently there is a wide range of internal shading devices including venetian, roller, pleated, panel, vertical and mid-plane blinds, shutters, screens, and tensile structures. The range of external devices also includes roller and venetian blinds, both fixed and moveable louvre arrays, tensile structures, canopies and awnings. Like the structure of shading products, shading properties also vary and blinds may be opaque, dim-out, semi-transparent, sheer or perforated screen. Early blinds were all manual, but the market now includes motorised shading products that were initially developed because manual operation was difficult or impossible in some locations; motorisation is continually evolving and building façades can now include automated 'intelligent envelopes' that react and change in response to the exterior climate and position of the sun. Although the majority of interior shading products remain manually-operated mechanical products, the number of motorised and automated products is increasing in keeping with user interest in electric products.

\section{The functions and benefits of blind use}


Blinds and shutters have various functions which can be divided into two main groups namely:

- $\quad$ Psychological: aesthetics, fashion, privacy and safety

- Practical: as contributors to thermal and visual comfort well-being and productivity, energy saving and security.

Aesthetics tend to be the main driver of choice for end users and specifiers (such as architects), even though the practical functions have a more significant long-term impact on the environment and building occupants. If specified and used correctly, shading products attenuate daylight and reduce thermal gain during the day and thermal loss during the 'heating season' and at night. In fact theoretical models show that they can save up to 15 percent energy when used with double glazed windows (Dolmans, 2006) and 25 percent energy when used with single glazed windows (ㅂutchens, 2015). While temperature control and thermal comfort can improve productivity in the workplace, it is essential for the wellbeing of very old and very young people, both of whom can suffer from ill health and even death if exposed to low or high temperatures for prolonged periods in the interior environment.

\section{Blind technology and user behaviour}

Currently in the UK many blinds are incorrectly specified or underused (i.e. they are raised and lowered infrequently) and therefore many of the benefits listed above are not fully realised. This may be due to the fact that the majority of blinds in residential properties are manually operated, although residents' behaviour and blind use may change if more motorised blinds are installed as illustrated in a European study which shows that motorisation encourages user engagement and 
residents raise and lower motorised blinds more frequently than manual blinds (Paule et al., 2015). Motorised products are either hardwired or battery operated and controlled with a handheld or attached device. The installation of external and internal motorised and automated shading systems is increasing in both residential and non-residential buildings; interestingly in this setting users prefer motorised and semi-automated blinds to fully automated blinds because they can control them to suit their personal preferences (Frontczak et al., 2012). The environmental impact of this type of blind is higher of course than that of manual blinds because they include electrical and electronic components. However, Life Cycle Assessment studies show that the environmental benefits derived from the energy savings associated with blind use outweigh the embodied impact of manual blinds (Andrews et al., 2015) and outweigh the embodied and operational impact of motorised blinds (Andrews et al., 2016).

\section{Market size and growth}

It is estimated that 50 million blinds are already installed in homes in the UK where annual sales of blinds typically exceed $£ 550$ million (AMA Research, 2014). This equates to between 4 and 5 million individual products, about 80 percent of which are residential sales and 20 percent nonresidential and, although some are replacement products, many are new sales. A number of factors indicate that both markets will increase: for example, the UK government plans to build 1 million new homes between 2015 and 2020. Sales will also increase as the functional benefits of blinds and shutters are becoming more widely recognised and new building performance guidelines that balance wellbeing and environmental factors are being developed. At present, average product life span varies from 5-20 years; length of life is influenced by quality and 
durability of components, the way in which blinds are used and maintained and frequency of decoration, which tends to be every five years on average; this activity may involve replacement of blinds for aesthetic reasons rather than because they no longer work and consequently many functioning products are wasted.

It is evident that millions of tonnes of materials and kilowatts of energy are embodied in this product sector and it is estimated that 3,000-5,000 tonnes of materials end up as waste every year in the UK alone because reprocessing is limited. We now discuss the various factors related to a Circular Economy (CE) for this sector.

\section{The design and manufacture of blinds}

Many complete (readymade) blinds and components (including the majority of motors and batteries for motorised and automated blinds) are now imported from China, for example. Nevertheless, there are still a number of major component manufacturers in Europe and the UK where the blind and shutter industry is well-established and semi-industrialised. It evolved as a cottage industry alongside the interior furnishing industry, and although several companies employ 500+ workers, about 75 percent of businesses employ 1-5 people. Larger businesses either manufacture or buy in components and assembly is machine-based but in many small businesses components are bought in and products are assembled by hand (Experian, 2014). Both historical and current business practice have therefore influenced the design and manufacture of the three groups of blind components (operating, shading and fixing), the majority of which push or snap fit together. 
Many of the mass-produced operating components are made from single polymers, but some are comprised of sub-components made from different materials; these include different types of polymer or polymers and metals. The shading components are also made from single materials (e.g. textile, aluminium and wood) and from composites (including polyester laminates and resin and glass fibre). Many are manufactured to standard dimensions while others cut to size for bespoke blinds; the majority of these components are then sewn by machine although some producers still sew by hand. Finally, when complete, the blinds are installed using mechanical fixings such as screws. The fact that the blind and shutter industry evolved alongside the furnishing industry has a major influence on perception of shading products and rather than being seen as building or architectural components, they are still frequently regarded as fixtures and fittings and, consequently, their perceived value is often relatively low.

These are all important considerations for the CE because they influence overall product lifespan, final treatment at end-of-life and will influence any recommendations for changes in practice.

\section{Current business practice and the $\mathrm{CE}$}

In addition to manufacture and installation a number of businesses in the UK and Europe specialise in the cleaning, maintenance, repair and refurbishment of blinds, all of which extend product life. These activities are partly facilitated by current component design in that they have been developed for assembly by hand and/or machine and the majority push or snap fit together. As a result, disassembly of complete components can be relatively uncomplicated (although it can be time-consuming). In some instances however, components are designed for one-way fit in 
which case they may be destroyed and replaced as part of the maintenance, repair and refurbishment procedure. Currently, the focus of service companies tends to be non-residential properties where maintenance contracts are commonplace. There are also a number of products on the market to aid cleaning and maintenance of domestic blinds, but this is not the case for repair and consequently many domestic blinds that could be repaired are replaced. The cost of professional maintenance and repair may also be higher than replacement, which also discourages repair of residential blinds.

Some manufacturers offer blind refurbishment services where operating components are reused and shading components are changed to compliment new decorating schemes, for example. This service tends to apply to roller or Roman-type textile blinds because it is easier, quicker and more cost effective to replace textile panels than louvres or slats, for example. Product refurbishment can extend blind life by many years but eventually these products will reach end-of-life which is now discussed.

\section{Shading products at end-of-life (EoL) and the Circular Economy (CE)}

Although there is no scientific data about treatment at end-of-life in the UK or Europe, anecdotal information indicates that the location where the blinds are installed (housing or otherwise) and type of installers (residents or businesses) influence treatment at end-of-life and that the predominant scenarios are the same as those for many other products:

- Being sent to landfill as waste - where all material value is lost 
- $\quad$ Being incinerated as waste - where all material value is lost

- $\quad$ Being incinerated with energy recovery - where some value is recovered

- $\quad$ Partial recycling - where some material value is recovered

In the UK, many blinds from the residential sector end up in municipal waste sites if disposal is the responsibility of the homeowner/resident, in which case they are either sent to landfill or incinerated with energy recovery. There is some evidence of reuse when blinds are resold through second-hand or charity shops, but this is relatively infrequent. Whether this is typical in countries with comparatively high general recycling rates is unknown; it is possible that reuse and recycling rates are higher than the UK if special collection points or services have been established and/or there is a culture of disassembly and component separation among residents.

Blinds can end up as construction 'waste', although this is becoming less common because materials with economic value (especially metals) tend to be removed from buildings prior to the final demolition. If the blinds are not removed and become mixed with the other rubble to become hard core that is used in new construction projects, however, it could be argued that they have retained some value and have been downcycled.

When blinds are replaced by professional sales and installation companies (who service both the residential and non-residential markets) the redundant products tend to be recycled in part. The blinds are partly disassembled and components are separated; the major metal components are stripped out and recycled along with off-cuts from the manufacturing and assembly process while mixed-material, composite, polymeric and textile components are usually disposed of as general waste. In this context, recycling is incentivised by relatively high commercial waste disposal charges and the payment for metals; this is not the case for 
homeowners/residents who have no financial incentives to recycle. Recycling rates may increase as more motorised and automated blinds are installed because they include electric motors, batteries and other electronic components. Although these blinds have a higher environmental impact than manual blinds, they could encourage circular behaviour because owners are obliged to recycle at end of life to meet Waste Electrical and Electronic Equipment (WEEE) legislation.

\section{What can designers do to encourage a more $\mathrm{CE}$ for this sector?}

It is evident that activities associated with the CE are already well-established in the blind and shutter manufacturing and allied service industries, but there is potential to improve and extend these activities by redesigning products and services. These changes could also be economically beneficial to the industry and end-users, reduce environmental impact and conserve resources, although introduction will probably depend on economic viability. For example:

- Design components that enable damage-free disassembly: change one-way push fit parts, e.g. ensure they deform for separation.

- Design components that enable rapid disassembly.

- $\quad$ Reduce the number of components that are comprised of more than one material: component materials are selected for their specific properties, however, so if it is not possible to substitute material types then redesign the sub-components to ensure that they can be easily separated.

- $\quad$ Encourage repair at home: design and sell repair kits with easy-to-follow guides. 
- Increase refurbishment services by manufacturers and at home to extend the life of operating components.

- Design guides to educate customers about maintenance, repair and refurbishment and include information (and possibly a tool) to encourage disassembly and separation of parts for recycling. Add the guides to all blind packages.

- Develop more comprehensive business service models where companies own blinds and 'sell shading'. Examples exist in the non-residential sector, but this could be extended to the residential sector: this model will encourage better management over product life which will aid maintenance and repair (which will extend product life) and treatment at end-of-life (which will increase recycling rates). Improved product management will also encourage component harvesting and remanufacture where appropriate and component reuse. In this case, durability will have to be monitored but this can be carried out as part of regular maintenance services.

\section{Conclusion}

This chapter began by briefly describing the history of shading products, their functions and benefits arising from use. It then discussed user behaviour and the fact that these benefits are not fully realised at present; however, motorised blinds increase user interaction, which will reduce energy consumption for heating and cooling and increase thermal and visual comfort. Although motorised blinds have a higher environmental impact than manual blinds, LCA shows that the environmental benefits deriving from 'correct' use outweigh these impacts. LCA also shows that 
product refurbishment and recycling of some if not all components at end-of-life is environmentally beneficial.

The UK shading product market is already large and will increase concurrently with the construction of new buildings and the introduction of new standards for well buildings. The blind and shutter industry is also well-established and includes many examples of good practice that are integral to the $\mathrm{CE}$, but there is room for improvement. The development of $\mathrm{CE}$ in the sector can be accelerated by several changes in component design and business practice which will extend product life and reduce waste of materials and embodied energy by facilitating repair, refurbishment, component harvesting, reuse and recycling at end-of-life. This will of course be dependent on the introduction of take-back schemes and manufacturers can encourage user participation through 'loyalty' discounts for replacement blinds, for example.

At present, the residential market is four times larger than the non-residential market, but there is little evidence of these circular activities in that sector and consequently a considerable quantity of materials and embodied energy are wasted. Furthermore, waste will increase concurrently with the predicted increase in sales. Some of the design proposals could encourage more circular behaviour by building occupants, but they must be supported by the introduction of comprehensive service-based business models that allow for professional management through all stages of the product life cycle. There are already examples of excellent practice in the blind and shutter industry, but they can be improved and extended through design and its importance in the development and implementation of a fully CE for this sector should not be underestimated. 


\section{Bibliography}

AMA. (2014). Research Domestic Window Coverings Market Report: UK 2014-2018 [Online]. Analysis Available at: www.amaresearch.co.uk/Window_Coverings.html [Accessed 20 July 2015].

Andrews, D., De Grussa, Z., Chalk, A., and Bush, D. (23-25 November 2015). Using Life Cycle Assessment to Illustrate the Benefits of Blinds as Passive and Sustainable Energy Saving Products in the Domestic Environment in the UK Going North for Sustainability: Leveraging Knowledge and Innovation for Sustainable Construction and Development. London: South Bank University.

Andrews, D., De Grussa, Z., Lowry, G., Newton, E., Chalk, A., and Bush, D. (2016). The use and impact of manual and motorised blinds as aids to thermal and visual comfort in domestic buildings in the UK. AMPs Journal. Special edition Volume 12, Living and Sustainability: An Environmental Critique of the Building Practices of Housing, Locally and Globally.

Dolmans, D. (2006). Energy Saving and $\mathrm{CO}_{2}$ Reduction Potential from Solar Shading Systems and Shutters in the EU-25 [Online]. Available at: www.esso.com/images/downloads/ESCORP-EU25\%20volledig.pdf [Accessed 20 July 2015].

Experian Business Database. (2014). [Online]. Available at: www.experian.co.uk/assets/businessinformation/brochures/National_Business_Database_Guide.pdf [Accessed 20 July 2015].

Frontczak, M., Andersen, R.V., and Wargocki, P. (2012). Questionnaire survey on factors influencing comfort with indoor environmental quality in Danish housing. Building and Environment 50: 56-64 [Online]. Available at: 
http://orbit.dtu.dk/files/6325199/Frontczak\%20et\%20al\%20Questionnaire\%20survey\%20 on\%20factors\%20influencing\%20comfort $\% 20$ with\%20indoor\%20nvironmental.pdf [Accessed 5 October 2016]. DOI: 10.1016/j.buildenv.2011.10.012.

Hutchens, M.G. (2015). High Performance Dynamic Shading Solutions for Energy Efficiency in Buildings [Online]. Available at: www.esso.com/images/downloads/Downloads\%20presentations/ES-SO_RT2015_Hutchins-M_V6_final.pdf [Accessed 20 July 2015].

Paule, B., Boutillier, J., and Pantet, S. (2015 ). Global Lighting Performance, Annual Report 2013R2014. Project 81 0083: Swiss Federal Office for Energy [Online], Lausanne. Available at: http://www.eso.com/images/downloads/Downloads\%20publications/ESTIA_Study_Engli sh_ver_3_0.pdf [Accessed 21 July 2016]. 